\title{
Bubble behavior in subcooled flow boiling in a vertical rectangular channel
}

\author{
Rouhollah Ahmadi \\ PhD candidate, Department of Mechanical \\ Engineering, Osaka University 2-1, Yamadaoka, \\ Suita-shi, Osaka 565-0871, Japan \\ phone: +81-6-6879-7257; \\ E-mail:ahmadi@ihmt.mech.eng.osaka-u.ac.jp
}

\author{
Tatsuya Ueno \\ Student, Department of Mechanical Engineering, \\ Osaka University 2-1, Yamadaoka, Suita-shi, \\ Osaka 565-0871, Japan \\ phone: +81-6-6879-7257; \\ E-mail:ueno@ihmt.mech.eng.osaka-u.ac.jp
}

\author{
Tomio Okawa \\ Professor, Department of Mechanical \\ Engineering, Osaka University 2-1, Yamadaoka, \\ Suita-shi, Osaka 565-0871, Japan \\ phone: +81-6-6879-7257; \\ E-mail:t-okawa@mech.eng.osaka-u.ac.jp
}

Keywords: subcooled flow boiling, bubble behavior, void fraction, Onset of nucleate boiling (ONB), OSV

\begin{abstract}
In this study bubble behavior in subcooled flow boiling in an upward rectangular channel was discussed. Filtrated and deionized tap water was used as a working fluid. Heated surface is produced by cupper with high wetability or low contact angle $\left(18^{\circ}\right)$. Subcooled flow boiling is beginning with onset of nucleate boiling (ONB) which surface temperature is higher than saturation temperature while liquid temperature is less than saturation temperature. At various pressure, mass fluxes and inlet temperatures ONB heat flux is detected within observation incipient nucleate bubbles through high speed video camera. Comparing with available ONB correlations, it is revealed that surface wettability is a significant parameter. Among $\Delta \mathrm{T}_{\mathrm{w}, \mathrm{ONB}}$ correlation only Basu et al. (2002)'s correlation has a good consistency with experimental data, and other correlations are most underpredicted. Nucleation rate of bubbles after ONB remain in very small amount until a specific condition nominated onset of significant void (OSV) or incipient point of net vapor generation (IPNVG) that void fraction drastically increased. Levy (1967) was the first to postulate bubble departure mechanism for OSV and many researchers believed this assumption and analytically and empirically proposed OSV correlation. However, in all the experimental conditions even at incipient bubble nucleation, bubbles are observed depart or lift-off from activated nucleation site on the heated surface. Bubble nucleation behavior as whether bubble Lift-off from hot surface or sliding along it are investigated. It is performed for low void fraction condition. It is concluded that lifting-off condition occurred when bubble size and subcooling temperature is high and sliding
\end{abstract}

phenomena in the opposite condition happened. Bubble size dramatically drop down after atmospheric pressure. This categorization is useful for developing new OSV mechanism regarded to actual situation.

\section{INTRODUCTION}

In subcooled flow boiling, creation of bubble started with location of onset of nucleate boiling (ONB) which surface temperature is higher than saturation temperature while liquid temperature is less than saturation temperature. At that moment, regarding to single phase flow, different heat transfer phenomena comes in to play. Several studied have been performed to finding out best correlation for ONB. Review literature lead to this fact that all of studies are based on Hsu (1962)'s criteria. He postulated that for an embryo bubble, temperature should be equal to saturation temperature at tip of the bubble. Bergles and Rohsenow (1964), Sato and Matsumara (1964) and Davis and Anderson (1966) are the famous researchers who express ONB heat flux in term of excess wall temperature empirically and analytically. Briefly, these correlations are expressed respectively here:

$$
\begin{aligned}
& q_{w, \text { ONB }}=1082 P^{1.156}\left(1.799 \Delta T_{w}\right)^{2.3 / p^{0.0234}} \\
& q_{w, O N B}=\frac{k_{l} h_{f g} \rho_{v}\left(\Delta T_{w}\right)^{2}}{8 \sigma T_{\text {sat }}} \\
& q_{w, O N B}=\frac{k_{l} h_{f g} \rho_{v}\left(\Delta T_{w}\right)^{2}}{8 C_{1} \sigma T_{\text {sat }}}
\end{aligned}
$$

Where, $\mathrm{C} 1=1+\cos \varphi$ and all other parameters are introduced in 
the nomenclature. According to these relations, only Davis and Anderson proposed correlation involved heated surface properties.

Recently, Basu et al. (2002) have experimentally studied subcooled flow boiling on copper flat plate and bundle of Zircalloy-4 tube for different surface contact angle. Several subcooled flow boiling experiments were performed while varying the flow rate and inlet subcooling with water at one atmosphere pressure. They found that for flat plate $(\varphi=30$ deg) past $\Delta \mathrm{T}_{\mathrm{w}, \mathrm{ONB}}$ correlations (Eq. 1-3) underpredict $\Delta \mathrm{T}_{\mathrm{w}, \mathrm{ONB}}$ in most cases compare to experimental data. In the other words, in same flow condition $\Delta \mathrm{T}_{\mathrm{w}, \mathrm{ONB}}$ tend to increase as well as wetability of surface increase. Therefore, they try to correlate $\Delta \mathrm{T}_{\mathrm{w}, \mathrm{ONB}}$ regarding to surface wetability or surface contact angle. They accepted Hsu's criteria but he assumed that probability of available cavity size corresponding to minimum wall superheat calculated from Hsu's criterion diminished as the wetability of the surface increases. Thereby, he expressed available cavity size as:

$$
D_{c}=D_{c}^{0} F
$$

Where, the correction factor $F$ (which depends on $\varphi$ ) is obtained empirically and $\mathrm{D}^{0}{ }_{\mathrm{c}}$ is obtained by invoking the minimum superheat criterion as,

$$
D_{c}^{0}=\left[\frac{8 \sigma T_{s a t} k_{l}}{\rho_{v} h_{f g} q_{w}}\right]^{1 / 2}
$$

From the available data, they expressed the function $\mathrm{F}$ as:

$$
F=1+\exp \left[-\left(\frac{\pi \varphi}{180}\right)^{3}-1.5\left(\frac{\pi \varphi}{180}\right)\right]
$$

Finally, they accepted Hsu's criterion and with approximation expressed $\Delta \mathrm{T}_{\mathrm{w}, \mathrm{ONB}}$ in terms of $\mathrm{D}_{\mathrm{c}}$ and $\mathrm{q}_{\mathrm{w}, \mathrm{ONB}}$ in terms of single phase heat transfer coefficient as:

$$
\begin{aligned}
& \Delta T_{w, \text { ONB }}=T_{w, \text { ONB }}-T_{\text {sat }}=\frac{4 \sigma T_{\text {sat }}}{D_{c} \rho_{v} h_{f g}} \\
& q_{w, O N B}=h_{s p}(z) \Delta T_{w, O N B}+h_{s p}(z)\left(T_{s a t}-T_{l}(z)\right)
\end{aligned}
$$

Nucleation rate of bubbles after ONB remain in very small amount until a specific condition nominated onset of significant void (OSV) or incipient point of net vapor generation (IPNVG) that void fraction drastically increased. Particular attention in this study was paid to bubble behavior. Levy was the first one to postulate bubble departure as a mechanism of OSV. He and many researchers are believed that bubbles have been stick on their nucleation site form ONB till OSV and bubble departure is a reason of onset of significant void in subcooled flow boiling. Many analytically and experimentally studies have been performed for finding out mechanism of OSV. Some researcher such as Dix (1971) observed bubble departure before OSV and indicate bubble departure alone is not sufficient to represent point of OSV. Some researcher such as Saha and Zuber (1974) believed Levy's theory only for high mass flux. Saha and Zuber collected all experimental data in Stanton versus Peclet
Number diagram. They proposed two different NVG mechanisms: at low mass fluxes NVG is controlled by local thermal conditions, whereas at high mass fluxes it is hydrodynamically controlled. They interpreted their correlation relaying on other researcher observations and experimental data. They believed bubble can be detached from nucleation site when Stanton number exceed from 0.0065 . Furthermore, in low flow rate Nusselt number (as defined in their paper) should be exceed from 455 to achieve OSV. Therefore, bubble can detach from surface and move close to the wall till Nusselt number reach to this specific amount. On the other hand, in high flow rate Nusselt number is already more than 455 , but Stanton number is less than 0.0065. Therefore, before OSV bubble cannot detach from surface but as soon as bubbles are detached from the surface, after Stanton number reach to 0.0065 , they can move to the liquid core and increase void fraction drastically.

Lee and Bankoff (1998) reviewed all the farmer researches for NVG. They focus on the correlation, not on the mechanism, and concluded Saha and Zuber is the best correlation that consists with the experimental data.

Totally, So far there has been no obvious mechanism that determines and explains definitely that what happen after OSV that void drastically was increased. Therefore, the objective of this study is identifying parameters that affect on bubble behavior. Particular attention in this study is paid on the bubble behavior in low void fraction. Several experiments from 1 to 8 bar operating pressure and wide range of water flow rate and liquid subcooling are covering this study.

\section{EXPERIMENTAL DESCRIPTION}

Filtrated and deionized tap water was used as a working fluid. It was kept boiling for about an hour in a vessel containing heaters for degassing. Figure 1 depicts the schematic diagram of the experimental loop. It was vacuumed prior to the experiment to remove air and supply the working fluid from the boiling vessel by means of pressure difference. A canned motor pump was used to drive the working fluid through the test loop. The total mass flow rate was measured using a turbine flow meter. The fluid was preheated using two $5 \mathrm{~kW}$ sheath heaters to set the inlet subcooling, then injected to a bypass line and a test section. The bypass line consisted of a stainless steel round tube of $5 \mathrm{~mm}$ in inside diameter and 1 $\mathrm{mm}$ in thickness. It was heated ohmically by passing a DC current to generate steam-water two-phase flow inside of it. The phase change in the bypass line was needed to keep the system pressure. The flow rate in the bypass line was also measured using a turbine flow meter. The remaining liquid entered the test section whose configuration is discussed later. After exiting the bypass line and the test section, the steam-water mixture entered the separator through an outlet header. Vapor phase was then sent to a condenser. The heat transfer rate in the condenser was controlled to maintain the system pressure. The fluid temperature was reduced to a subcooling state at the cooling section before returning to the circulation pump. Temperatures and pressures were measured using K-type thermocouples and pressure transducers. The measurement points are shown schematically in Fig. 1.

A schematic diagram of the rectangular test section is 


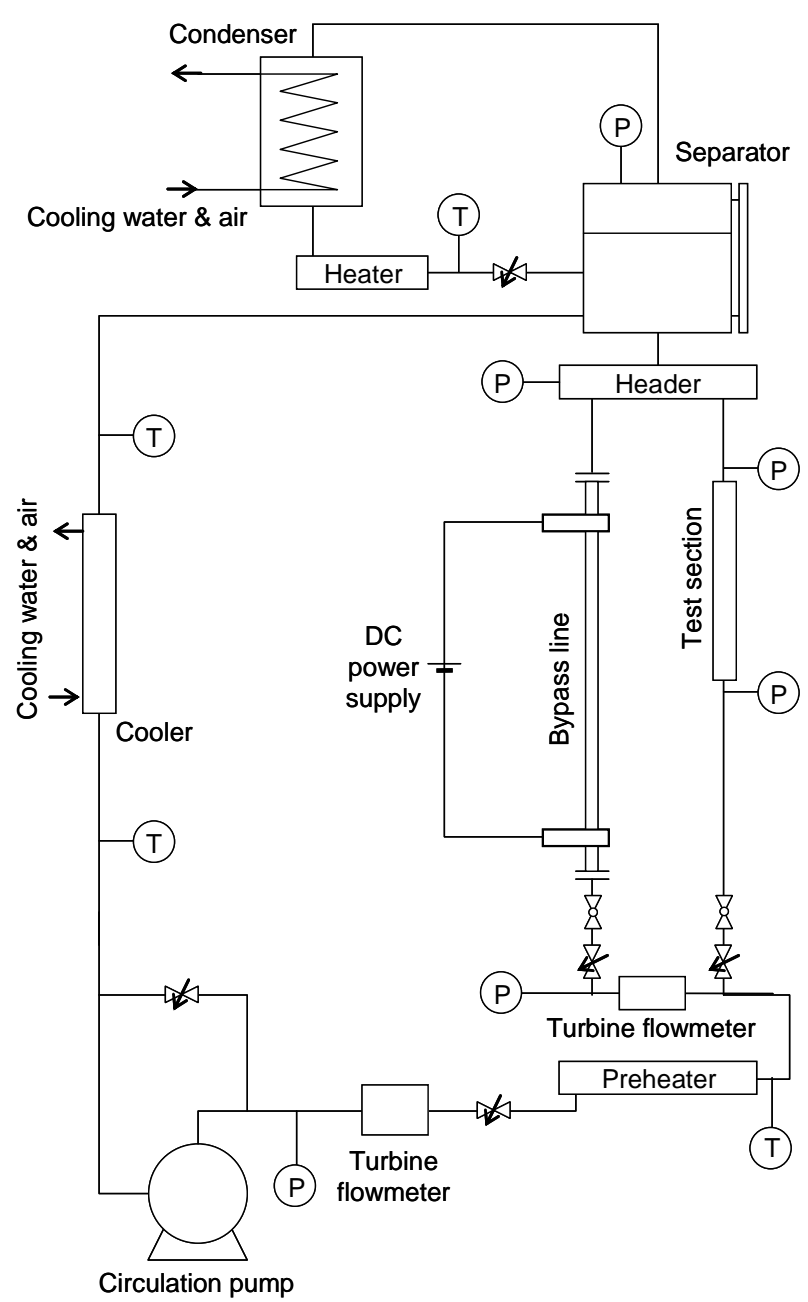

Fig. 1 Schematic diagram of experimental loop

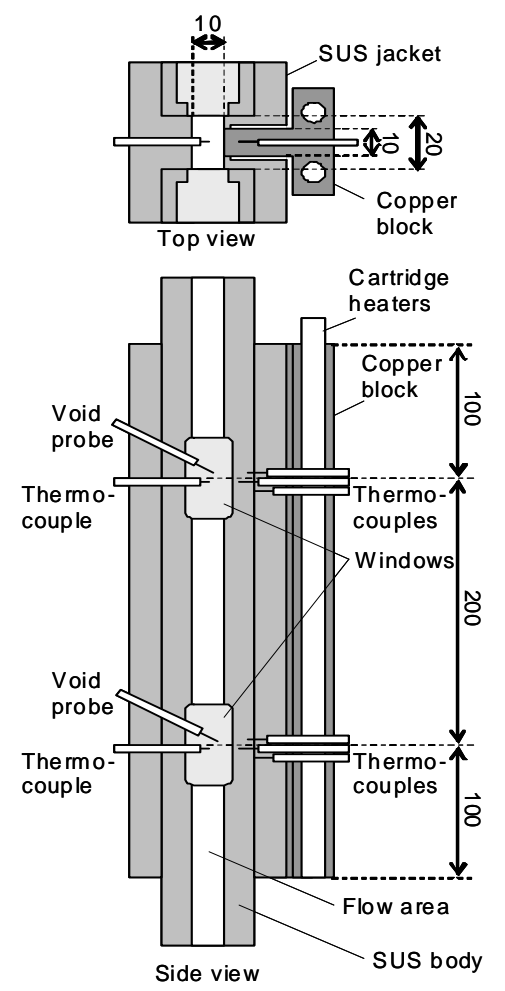

Fig. 2 Schematic diagram of test section depicted in Fig. 2. A main body of the test section was made of stainless steel. A copper block containing two $1.2 \mathrm{~kW}$ cartridge heaters was set on the main body to construct the flow channel. The flow area was rectangular in shape of $10 \mathrm{x}$ $20 \mathrm{~mm}$. As delineated in the top view in Fig. 2, the copper block was covered by the stainless steel jacket. The end face of the copper block of $10 \mathrm{~mm}$ in width was regarded as the heated surface. The present heated surface was rather hydrophobic and its contact angle was $18^{\circ}$. The copper block and the jacket were connected smoothly by means of electron beam welding to avoid significant boiling in the connecting region. The total heated length was $400 \mathrm{~mm}$. The test section had two measuring sections at 100 and $300 \mathrm{~mm}$ from the bottom of the heated section. At each measuring section, three thermocouples were embedded in the copper block to determine the wall superheat. The fluid temperature could be measured using a K-type thermocouple. In addition, two sets of glass windows were mounted at the measuring sections for visual observation of bubbles using a high-speed camera.

In the present experiments, measurements were performed at the upper measuring section. The pressure at the measuring section $\mathrm{P}$ and the inlet subcooling $\Delta \mathrm{T}_{\text {sub }}$ were set from 1 to 8 bar and 3 to $30 \mathrm{~K}$, respectively, and the mass flux $\mathrm{G}$ covering high range from low to high flow rate as $380-1170 \mathrm{~kg} / \mathrm{m}^{2} \mathrm{~s}$. Experiments were starting with increasing wall heat flux $\mathrm{q}_{\mathrm{w}}$ in constant pressure and mass flux and lowest amount of inlet water temperature till ONB. After ONB was determined, in order to identifying bubble behavior, slightly more heat flux applied on the heater. Throughout experiment all parametric data obtained by data acquisition and also nucleate bubbles were observed within high speed video camera. For the visualization, bubbles were backlight using a metal halide lamp. The visualization area was about $10 \times 10 \mathrm{~mm}$ and the spatial resolution was about 0.02 $\mathrm{mm} /$ pixel. The frame rate and the shutter speed were set to 6000 fps and $0.166 \mathrm{~ms}$, respectively.

\section{RESULTS AND DISCUSSIONS}

\section{$\underline{\text { 3.1 ONB detection and comparison }}$}

In subcooled flow boiling onset of nucleate boiling (ONB) is the point where first bubble appears on the heated surface. Therefore, experiment start with single phase and heat flux slightly increase step by step. Wall temperature increases as heat flux increase. With checking wall temperature as well as observing heated surface within high speed camera, ONB condition can be detected. Several experiments in high range of pressure, mass flux and temperature subcooling were performed to detecting ONB. Heated surface is hydrophilic and have an 18 degree contact angle. Comparison of the experimental data of $\Delta \mathrm{T}_{\mathrm{w}, \mathrm{ONB}}$ with former correlations (Eq.1-7) is shown in figure 3. As Basu et al. (2002) have mentioned in his research, ONB corrections according to Eq.1-3 underpredict $\Delta \mathrm{T}_{\mathrm{w}, \mathrm{ONB}}$ value respect to real state. Although in Davis and Anderson's correlation contact angle is included, but Basu et al.'s correlation can predict present experimental more accurately. Not only similarity of test section with Basu et al.'s test section may be one of the reasons of consistency, but low contact angle and more 


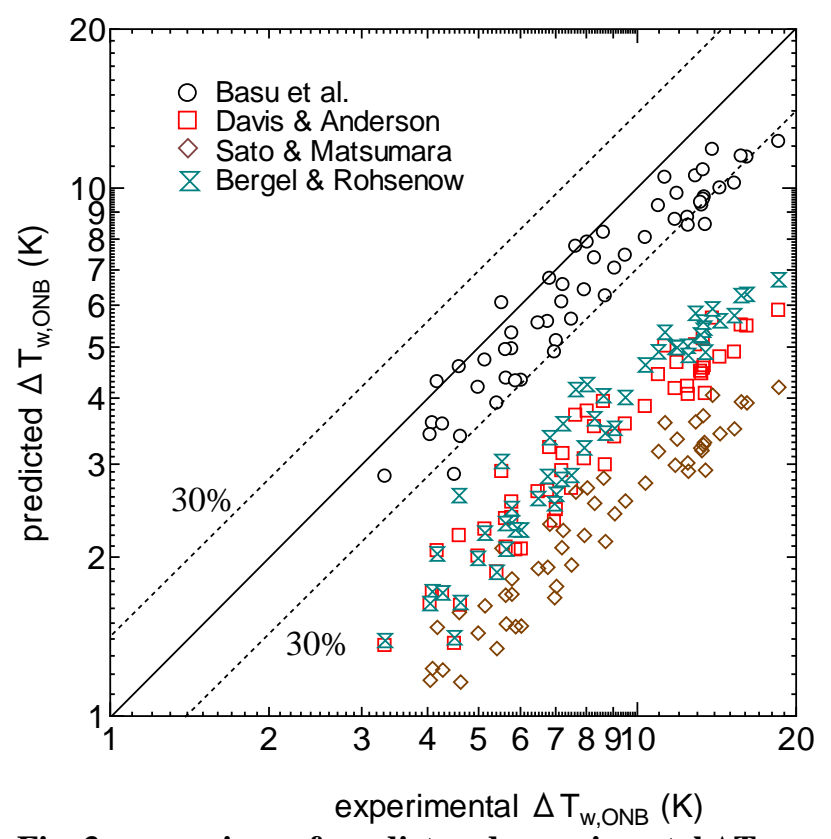

Fig. 3 comparison of predict and experimental $\Delta T_{w, O N B}$ value

sensibility of Basu et al.'s correlation to contact angle also can be assumed as a main reason. As a result, it can be concluded that the surface wetabablity property is a significant factor which affect on $\Delta \mathrm{T}_{\mathrm{w}, \mathrm{ONB}}$.

\subsection{Bubble behavior}

Observation of nucleate bubbles at ONB declares some important facts that can be useful for identifying void development mechanism. Bubble nucleation behavior as whether bubble detachment from hot surface or sliding along it are investigated. As mentioned before, Levy and many researchers have believed that bubbles have been stick on their nucleation site from ONB location until OSV, and bubble departure is a reason of onset of significant void in subcooled flow boiling. However, in the present study all the bubbles started lifting off or departing from their nucleation site from ONB location. For two different flow conditions, bubble lift off and bubble departure (bubble sliding) are shown in figure 4 (a) and (b), respectively. For more confidence about bubble behavior, in each set of experiment heat flux slightly increased and in this case bubble lift off and bubble sliding, are observed obviously, too. It should be noted that in industrial application and nuclear reactor vessel even fresh heated surface was hydrophobic, after operation, surface inclined to be hydrophilic. Therefore, hydrophilic surface was chosen. Accordingly, bubble detachment theory for OSV mechanism, in all flow conditions, should be forgotten and different mechanism should be determined in the future works.

Observation of bubbles during creation and leaving their nucleation site for various conditions reveals that small bubbles tend to move close and along to the hot surface, whereas large bubble after growing, lift off and collapses in the bulk liquid. For one case bubble size along flow direction $\left(D_{l}\right)$ and lateral direction $\left(D_{w}\right)$ was measured and shown in figure 5. Third dimension of ellipsoidal bubble, according to

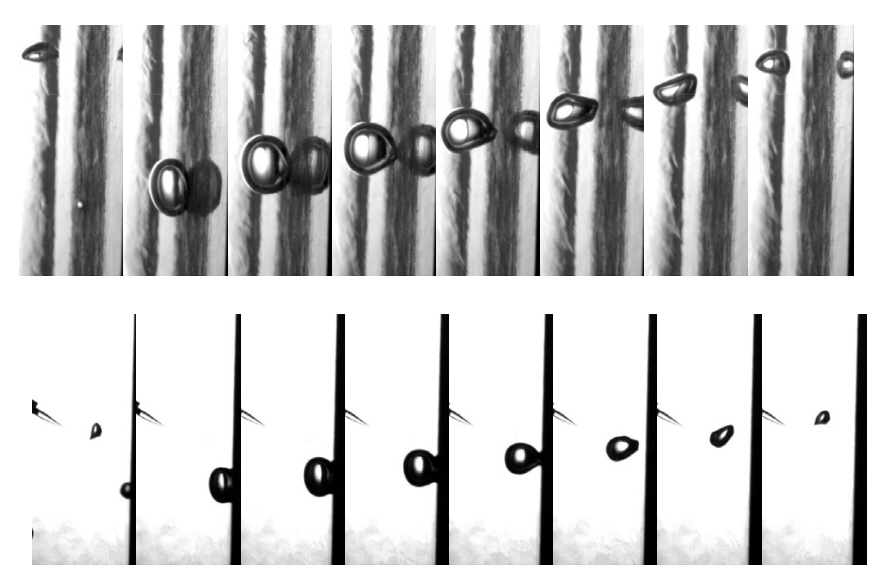

Fig. 4-a Bubble lift-off at $P=96.7 \mathrm{kPa}, \mathrm{G}=384 \mathrm{~kg} / \mathrm{m}^{2} \mathrm{~s}$, $\Delta T_{\text {sub }}=12.4 \mathrm{~K}$ (olique and parrallel view regarded to heated surface)

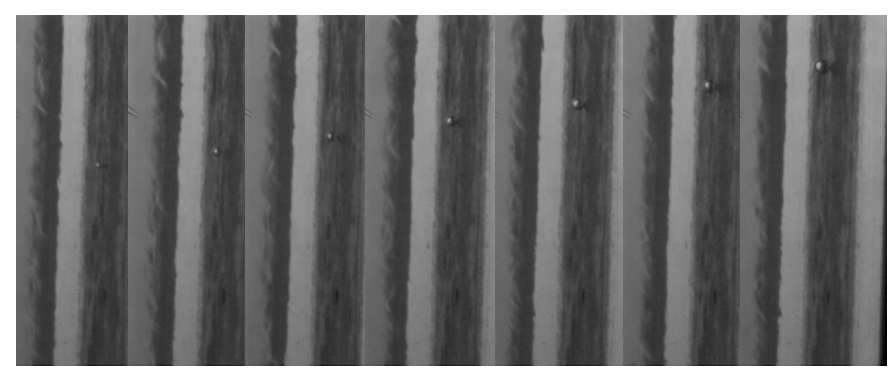

Fig. 4-b Bubble departure (sliding) at $\mathrm{P}=203.3 \mathrm{kPa}$, $\mathrm{G}=382 \mathrm{~kg} / \mathrm{m}^{2} \mathrm{~s}, \Delta \mathrm{T}_{\text {sub }}=10 \mathrm{~K}$

the oblique view of camera, was assumed as same as $D_{1}$. Therefore, according to these sizes and equivalent bubble volume, mean bubble diameter can be calculated. This value is depicted in figure 5, too. Several researchers studied bubble detachment phenomenon and proposed mechanism of bubble detachment. Recently, Lucic and Mayinger (2003) and Mayinger (2006) used holographic interferometry method for heat transfer study on bubble condensation during subcooled flow boiling. In upward subcooled flow boiling they measured Nusselt number around bubble diameter. While bubble is growing and lift-off always Nusselt number or heat transfer of back-side of the bubble is lower than frond-side (see figure 6). So, it can be concluded that condensation will take place back-side of the bubble.

In this study, bubble detachment mechanism is determined by tracing of the bubble behavior. As bubble attached to the heated surface is growing up mostly in longitudinal direction (see Fig. 5). After bubble is grown completely, volume of the bubble does not change significantly. Changing of bubble shape from ellipsoidal to spherical is started from backside of the bubble and seems to bubble slide slowly on the surface. At that moment, bubble completely has moved to the bulk liquid and disturbed boundary layer velocity and temperature around its shape, however, bubble still attached to the surface. When the bubble shape is spherical, fluid tend to push-up bubble due to the drag force whereas the surface tension force tend to keep bubble at the surface. Overlap images of bubble while it lifting-off from the hot surface is shown in figure 7 . Bubble that will be discussed is indicated by arrow 


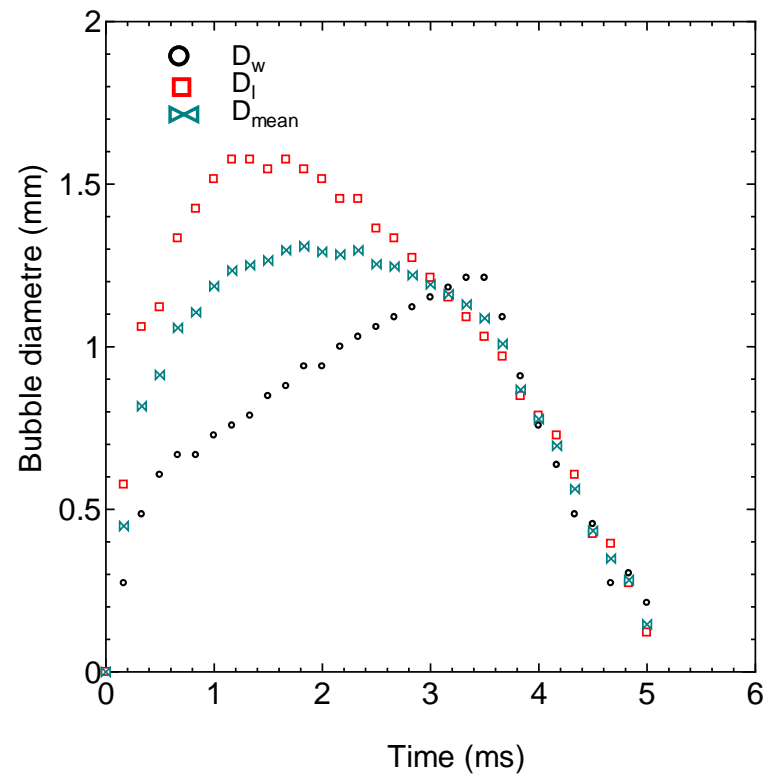

Fig. 5 Dimension of bubble while nucleate and collapse $\left(\mathrm{P}=96.7 \mathrm{kPa}, \mathrm{G}=384 \mathrm{~kg} / \mathrm{m}^{2} \mathrm{~s}, \Delta \mathrm{T}_{\mathrm{sub}}=12.4 \mathrm{~K}\right)$
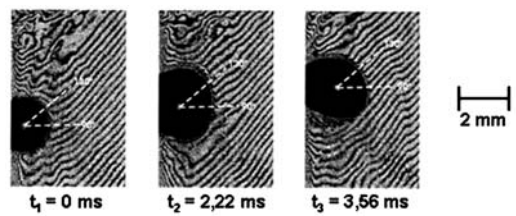

$\mathrm{t}_{2}=2,22 \mathrm{~ms}$

$\mathrm{t}_{3}=3,56 \mathrm{~ms}$

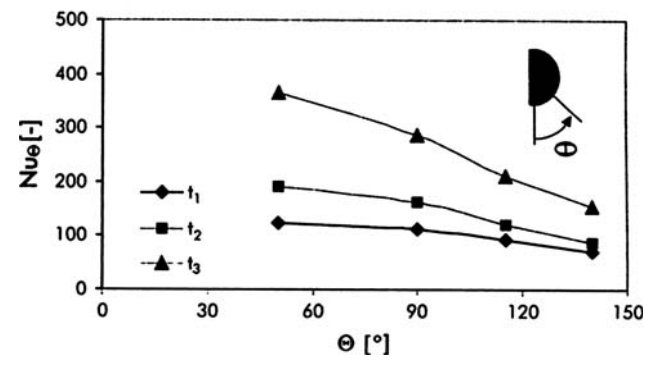

Fig. 6 Example of the heat transfer around abubble condensing in sucooled flow boiling [ Mayinger (2006)]

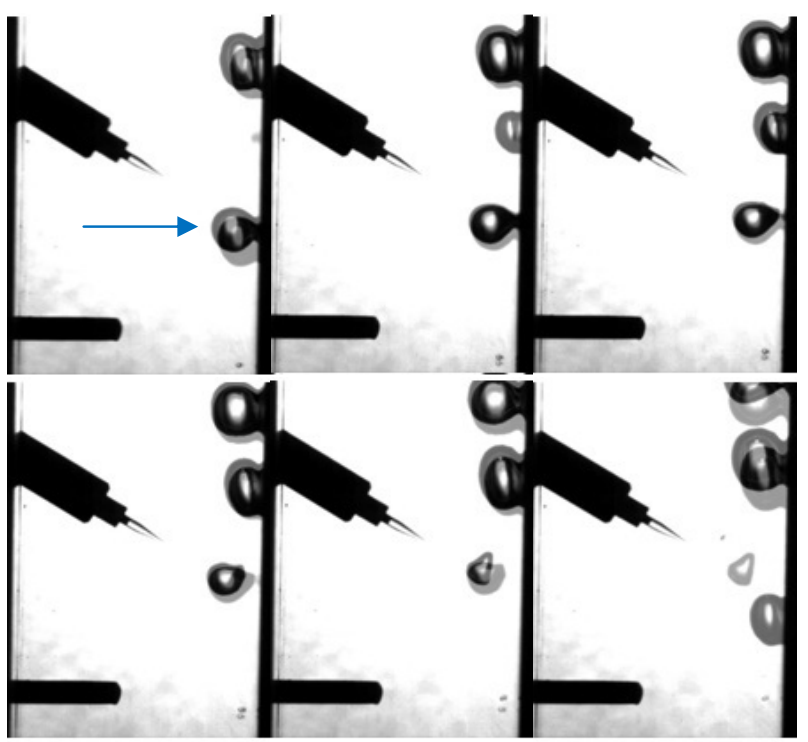

Fig. 7 Overlap bubble shape while Lifting-off $(P=96.7 \mathrm{kPa}$, $\mathrm{G}=384 \mathrm{~kg} / \mathrm{m}^{2} \mathrm{~s}, \Delta \mathrm{T}_{\text {sub }}=12.4 \mathrm{~K}$ ) in this figure. As shown in Fig. 7, bubble ceased at front-side and while attached to the surface is going to spherical shape. In next step, cold water of upstream flow faced with the big bubble and condensation started significantly from back-side of the bubble. As cold water inter to the super heated layer region, basis of the bubble where attached to the heated surface is cut out. In next step, bubble condensation is continuing from close to the wall to the bubble tip and then bubble disappears in the bulk liquid.

In the other hand, behavior of small bubbles can be interpreted with regarding to two subjects. First, small bubble cannot disturb velocity and temperature profile significantly and during departure is located in superheated layer. Therefore, probability of prompt condensation is low. Second, small bubbles can stay close to the hot surface because of lift force, which acts on the bubble in opposite direction of lift off. Therefore, small bubble can move close to the hot wall and due to the subcooled temperature value, some of them condensed and some of them survived.

In the prior study, Okawa et al. (2005) introduced sliding, bouncing and collapsing bubble. Their experiment performed around 1 bar and different flow rate. Therefore, they categorized bubble behavior according mass flow rate and amount of liquid subcooling. As pressure and mass flow rate increase nucleate bubble diameter rapidly decreased (see figure 8). Bubble behavior according bubble size is depicted in figure 8. Big bubbles exist only at low flow rate and

a)

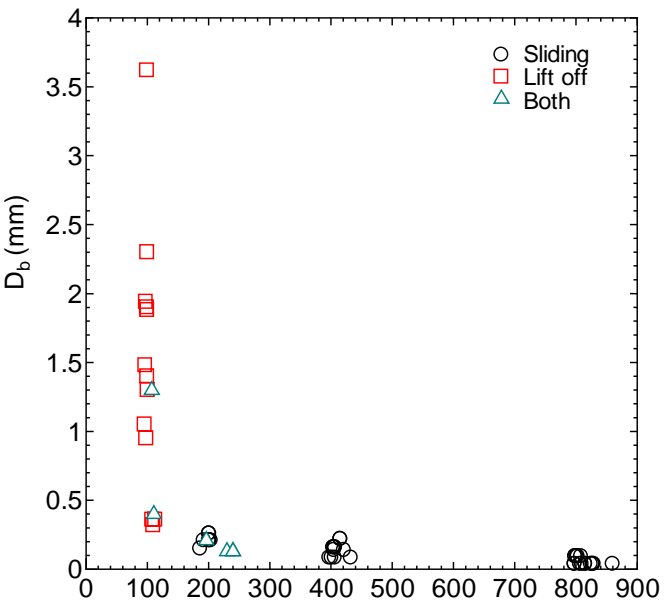

b)

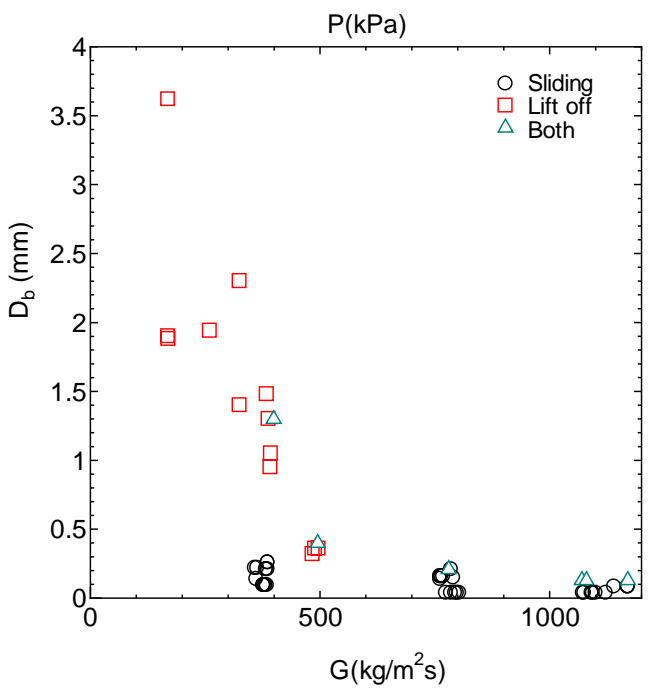

Fig. 8 Different bubble behavior in $P$ \& $G-D_{b}$ map

Copyright (C) 2011 by JSME 


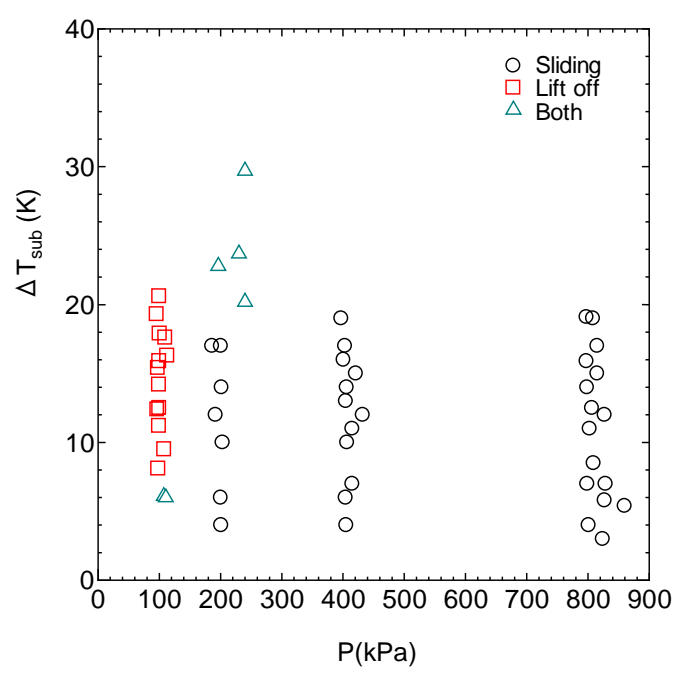

Fig. 9 Different bubble behavior in $P-\Delta T_{\text {sub }}$ map

atmospheric pressure, and they able to lift-off from the surface. In the other hand, regarded to this study, when pressure exceeds from atmosphere pressure, even at low flow rate bubble size is so small and cannot lift-off from the surface.

In figure 9 effect of subcooling is shown in versus liquid subcooling. According to this figure, for having lift-off condition at high pressure, high subcooled liquid should be applied on heated surface. Therefore, in addition to bubble diameter, liquid subcooling temperature effected bubble behavior whether lifting-off or sliding. However, as pressure exceed from atmospheric pressure bubble size will be influential parameter rather liquid subcooled temperature.

\section{CONCLUSION}

Bubble behavior at low void fraction is investigated in this study. Several experiments performed for detection ONB. Comparison of experimental data with available correlation resulted that for wettable surface, Busu at al.’s correlation can predicted $\Delta \mathrm{T}_{\mathrm{w}, \mathrm{ONB}}$ very well, and other former correlations underpredicted excess wall temperature. One of the results is that when wetability of the surface increase rarely of nucleation site will be activated and hotter surface is needed. Behavior of the bubbles in low void fraction is the main purpose of this study. Therefore, particularly attention from ONB to fairly higher than ONB (less than OSV) has been paid to bubble behavior as liftoff or slide. This behavior is very important, because it can lead to finding out OSV mechanism and compare to the prior OSV mechanism.

Levy and many researchers are believed that bubbles have been stick on their nucleation site from ONB to OSV and bubble departure is a reason of onset of significant void in subcooled flow boiling. However, in all the experimental conditions even at incipient bubble nucleation, bubbles are observed depart or lift off from activated nucleation site on the heated surface; hence the IPNVG is not directly related to the point of bubble departure that assumed in many models. Between ONB and OSV big bubbles can detached and collapse in the bulk liquid as well as small bubbles can depart and slide along heated surface. Therefore, OSV can have two different mechanisms according to bubble behavior. Bubble life time is important in lifted-off bubble, and influence of sliding bubble on downstream bubble is important in sliding bubble case. However, subcooled flow boiling are included a lot of parameters and phenomena; thereby explain about OSV mechanism need another opportunity to concentrate deeply on the experimental data and bubble behaviors.

It is concluded that the pressure is a significant influential factor on bubble size. And, nucleate bubble diameter is influential parameter on bubble behavior. Big bubble tent to liftoff and small bubble inclined to slide close the heater surface. Amount of the liquid subcooled temperature is another factor that effects on bubble lift-off and sliding behavior; however, whiles the pressure exceed from atmospheric pressure effect of subcooling diminished. In the other words, high subcooling should be applied on the heated surface until bubble be able to liftoff to the bulk liquid and collapse there.

\section{ACKNOWLEDGMENT}

This work was supported by KAKENHI (No. 20360419).

\section{NOMENCLATURE}

$\begin{array}{lll}c & \text { specific heat } & {[\mathrm{J} / \mathrm{kg} \cdot \mathrm{K}]} \\ D & \text { diameter } & {[\mathrm{m}]} \\ D^{0}{ }_{c} & \begin{array}{c}\text { cavity diameter corresponding } \\ \text { to the tangency condition }\end{array} & {[\mathrm{m}]} \\ & \text { mass flux } & {\left[\mathrm{kg} / \mathrm{m}^{2} \mathrm{~s}\right]} \\ G & \text { latent enthalpy } & {[\mathrm{J} / \mathrm{kg}]} \\ h_{f g} & \text { heat transfer coefficient } & {\left[\mathrm{W} / \mathrm{m}^{2} \cdot \mathrm{K}\right]} \\ h & \text { thermal conductivity } & {[\mathrm{W} / \mathrm{m} \cdot \mathrm{K}]} \\ k & \text { Nusselt number } & {[\mathrm{dimensionless}]} \\ N u & \text { Pressure } & {[\mathrm{Pa}]} \\ P & \text { Peclet number } & {[\mathrm{dimensionless}]} \\ P e & \text { heat flux } & {\left[\mathrm{W} / \mathrm{m}^{2}\right]} \\ q_{w} & \text { Stanton number } & {[\mathrm{dimensionless}]} \\ S t & \text { temperature } & {[\mathrm{K}]} \\ T & & \end{array}$

\section{Greek Letters}

$\begin{array}{lll}\alpha & \text { mean void fraction } & {[\text { dimensionless }]} \\ \rho & \text { density } & {\left[\mathrm{kg} / \mathrm{m}^{3}\right]} \\ \sigma & \text { surface tension } & {[\mathrm{N} / \mathrm{m}]} \\ \varphi & \text { surface contact angle } & {[\text { degree }]} \\ \Delta T & \text { temperature difference } & {[\mathrm{K}]}\end{array}$

\section{Subscripts}

$\begin{array}{ll}b & \text { bubble } \\ e & \text { equilibrium } \\ h & \text { hydraulic } \\ \text { in } & \text { inlet } \\ \text { IPNVG } & \text { incipient point of net vapor generation } \\ l & \text { liquid } \\ \text { OSV } & \text { onset of significant void } \\ s & \text { saturation } \\ \text { sp } & \text { single phase } \\ \text { sub } & \text { subcooled } \\ v & \text { vapor } \\ w, O N B & \text { wall, onset of nucleate boiling }\end{array}$




\section{REFERENCE}

A. Lucic, F. Mayinger, 2010, Transportphanomena in subcooled flow boiling, Heat Mass Transfer, Vol 46, pp 1159-1166

Bergles, A.E., Rohsenow, W.M., 1964, The determination of forced-convection surface-boiling heat transfer, ASME J. Heat Transf., Vol 1, pp 365-372.

Davis, E.J., Anderson, G.H., 1966, The incipience of nucleate boiling in forced convection flow, AIChE J., Vol 12 (4), pp 774-780.

F. Mayinger, 2006, Heat transfer at the phase interface of bubbles collapsing in subcooled liquids and during subcooled boiling, Heat Mass Transfer, Vol 42, pp 869-874

Levy, S., 1967, Forced convection subcooled boiling prediction of vapor volumetric fraction, International Journal of Heat and Mass Transfer, Vol. 10, pp 951-965.

Lee, S. C., Bankoff, S. G., 1998, A comparison of predictive models for the onset of significant void at low pressures in forced-convection subcooled boiling, KSME International Journal 12 (3), pp 504-513

N. Basu, G.R. Warrier and V.K. Dhir, 2002, Onset of nucleate boiling and active nucleation site density during subcooled flow boiling, Trans. ASME, J. Heat Transfer, Vol. 124, pp 717-728.

Saha, P., Zuber, N., 1974, Point of net vapor generation and vapor void fraction in subcooled boiling, Proceedings of 5th International Heat Transfer Conference, pp 175-179.

Tomio Okawa, Tatsuhiro Ishida, Isao Kataoka, Michitsugu Mori, 2005, Bubble rise characteristics after the departure from a nucleation site in vertical upflow boiling of subcooled water, Nuclear Engineering and Design, Vol. 235, pp 1149-1161 